Article

\title{
On the Use of Vibro-Compressed Units with Bio-Natural Aggregate
}

\author{
Mauro Sassu *, Linda Giresini, Elisa Bonannini and Mario Lucio Puppio \\ Department of Energy, Systems, Territory and Constructions Engineering, University of Pisa, \\ Largo Lazzarino 1, Pisa 56122, Italy; linda.giresini@unipi.it (L.G.); elisa.bonannini@virgilio.it (E.B.); \\ mariolucio.puppio@ing.unipi.it (M.L.P.) \\ * Correspondence: mauro.sassu@unipi.it; Tel.: +39-050-221-8215 (ext. 240)
}

Academic Editor: Francisco López Almansa

Received: 10 July 2016; Accepted: 13 September 2016; Published: 19 September 2016

\begin{abstract}
The paper deals with the use of vibro-compressed units with bio-natural components on construction. The proposed mix design of vibrated blocks consist of cork granules and/or hemp shives, with the aim to substitute polymeric elements or expanded clay, together with the use of natural hydraulic lime (NHL) as binder. An experimental campaign is presented, with mechanical tests to evaluate the influence of each component on flexural and compression behavior. The proposal is also investigated from a productive point of view, considering how it can be harmonized in the productive process of lightweight aggregate concrete units without modifications in the productive process. The tested elements could perform a certain reduction of the carbon impact, maintaining interesting mechanical properties. The application of the proposed units in several contexts, as separating elements joined with structural components, is considered to improve rehabilitation or to obtain higher performances in buildings.
\end{abstract}

Keywords: vibro compressed unit; bio natural component; NHL

\section{Introduction}

Existing constructions, especially with historical masonry load-bearing walls, are often characterized by poor mechanical properties, due to the use of not-engineered or not-properly-selected components, as experimentally observed in [1,2]. In other contexts the presence of humidity at the base of the walls is able to reduce the mechanical properties and the integrity of the constructions [3]. In these last cases, the application of specific reinforced damp proof courses [4] or temporary reinforcements [5] can mitigate this aspect. The application of smooth dissipating elements at the basement can also induce the interesting "biaxiality effect" during seismic motions [6]. Further progress can nevertheless be obtained in the mentioned cases by the adoption of bio-natural components: the types investigated here can be a possible choice. It should also take into account that the non-structural elements in seismic zones should be calculated, as requested by European regulations (Eurocode 8). Moreover, recent earthquakes (Abruzzo 2009, Emilia 2012-Italy) [3] showed that great damage, injuries and loss of life occurred due to the collapse of non-load-bearing elements as separating walls or façades or internal clay layers for thermal insulation.

In the last decade, the use of hemp in civil constructions has drawn the attention of producers and designers pointing out perspectives and difficulties in using hemp fibers or shives in construction [7-10]. In the same way, cork [11] or other recycled mixtures [12-14] are used as components in constructive applications. Hemp fibers or shives and cork granules, mixed with lime or cement, exhibit evaluable thermal and mechanical properties. In [14], vibrated compressed blocks made with hemp shives attained a thermal conductivity value of $0.34(\mathrm{~W} / \mathrm{m} \cdot \mathrm{K})$. In [8], values between 0.179 and $0.543(\mathrm{~W} / \mathrm{m} \cdot \mathrm{K})$ were obtained by using lime and hemp shives. In both cases, the material density was about $600 \mathrm{~kg} / \mathrm{m}^{3}$. 
Also the transient thermal properties together with the hygrometric ones are remarkable [15]. The construction process, including mechanical tests, was also tested on a full-scale building [16]. Concerning durability, the straw elements are not significantly exposed to organic attacks.

The cork granules are used in buildings mainly for insulating panels and finishing pavement layers [17], due to the capacity to resist compressive forces. The thermal properties are also favorable with a thermal conductivity of less than $0.05(\mathrm{~W} / \mathrm{m} \cdot \mathrm{K})$. Referring to mechanical properties, the black cork panels have a compression strength of $0.2-0.4 \mathrm{MPa}$ and similar values of flexural strength, whereas the Young's modulus is about 5.0 MPa. The cork is not strongly sensitive to organic attacks, although fungal colonization can influence its mechanical properties [18], and is fire resistant.

The natural hydraulic lime (NHL) is exclusively derived from natural marl or siliceous limestone, with only the addition of water as in EN 459-1 and ASTM C-141 regulations: it commonly performs with compression strength values between 2.0 and 5.0 MPa. Low-impact and environmentally friendly new aggregates and binders can be reasonably included in a large-scale constructive process whether they are easy to supply and cost-effective [19]. Moreover, they should have satisfactory mechanical properties and the mix design has to be workable. In this paper, an experimental campaign is reported. A selection of several mix designs has been done to perform a sufficient workability of the fresh mixture in a traditional factory to produce lightweight vibro-compressed concrete blocks; moreover, the fresh mix design after the vibro-compression phase should be able to maintain the shape of the block for the further curing phase. Mechanical tests are addressed to evaluate new mix design types for pre-cast masonry units. These masonry units can be applied on elements for vertical separating walls or as horizontal elements at the base of low-rise buildings to help RCW elements [4]. Those elements could also contribute to enforcing the capability of dissipating energy during rocking out-of-plane motions of walls [20], adding their role to the elastic restraints [21-23].

\section{Production Assessment}

A set of units with dimensions of $250 \mathrm{~mm} \times 120 \mathrm{~mm} \times 55 \mathrm{~mm}$ was produced in a factory of vibrated-compressed concrete blocks, by using molds to cast the fresh products. The components chosen for testing were hemp shives and cork granules, while the binder was pure NHL or NHL mixed with Portland cement.

Hemp shives (Figure 1) were selected with a thickness range from 0.5 to $1.5 \mathrm{~mm}$ and a length range from 6 to $15 \mathrm{~mm}$; those measurements were given by the supplier and verified by sieving and direct survey on spot elements. Cork granules, sub-products of previous production processing, were of the second category type with a diameter range from 2 to $3 \mathrm{~mm}$ (Figure 2) obtained by sieving. The NHL was supplied by an Italian factory, and classified as NHL3.5 (i.e., compression strength of $3.5 \mathrm{MPa}$ ). The entire mix design has been conceived to use low-cost, low-technology and environmentally friendly components. Five different mix design types have been prepared, four with hemp shives and one with cork granules, as follows:

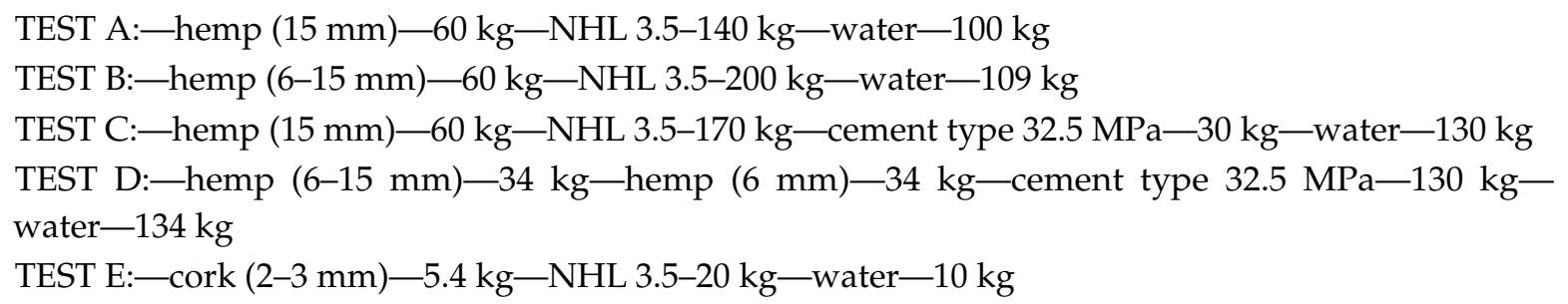

The blocks with mix design types from $A$ to $D$ have been produced by automatic vibro-compressed block-making machines. The block with mix design type $\mathrm{E}$ has been manually made in the fresh phase (Figure 3), i.e., the mix design was not automatically prepared by the production chain, but it was automatically vibro-compressed into the conveyor and moved for curing (Figure 4). The production chain is depicted in Figure 5. The aggregates were carefully selected to give a quality textured consistent finish with weight measurements. 


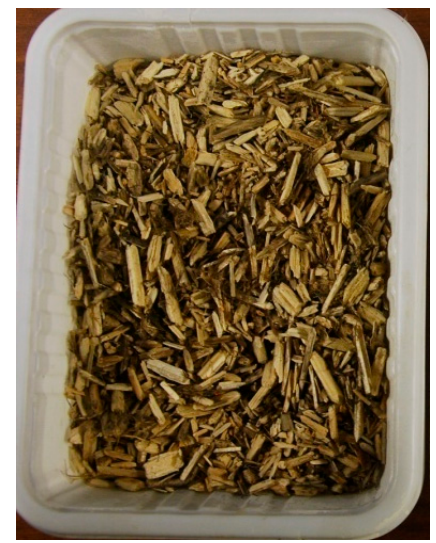

(a)

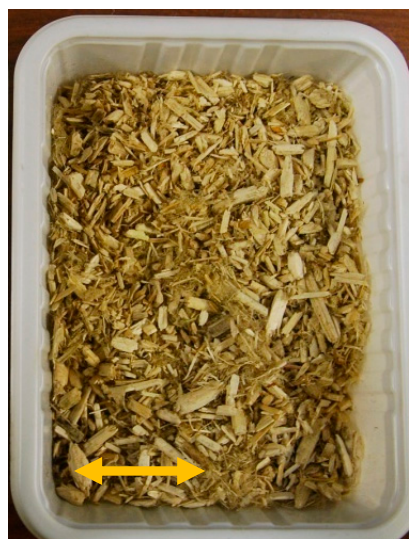

(b)

Figure 1. Hemp shives with average length of (a) $15 \mathrm{~mm}$ and (b) $6 \mathrm{~mm}$ (yellow unit $20 \mathrm{~mm}$ ).

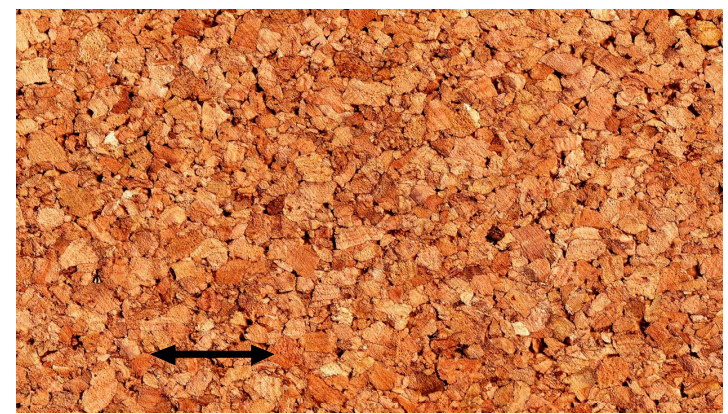

Figure 2. Cork granules with average diameter 2-3 mm (black unit $10 \mathrm{~mm}$ ).

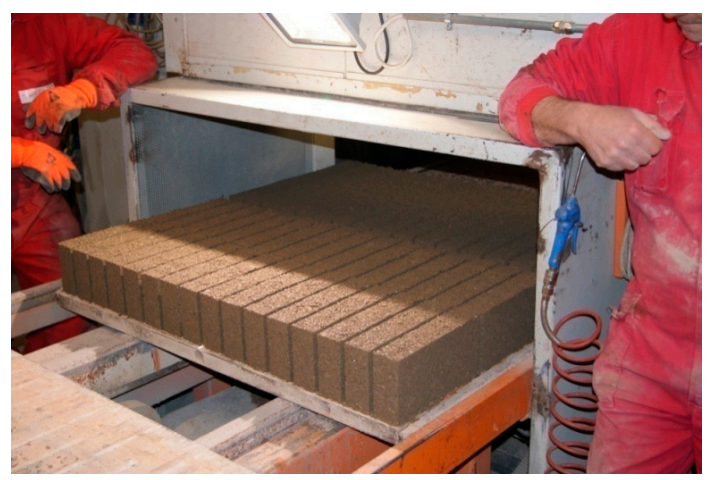

Figure 3. Fresh blocks outgoing from the mold box.

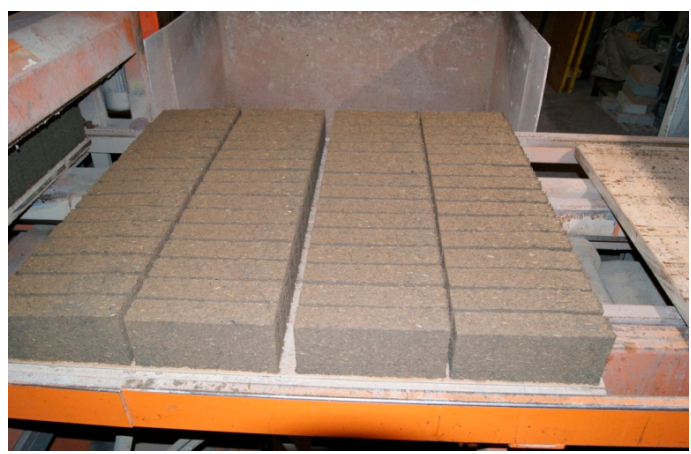

Figure 4. A set of blocks placed for curing. 


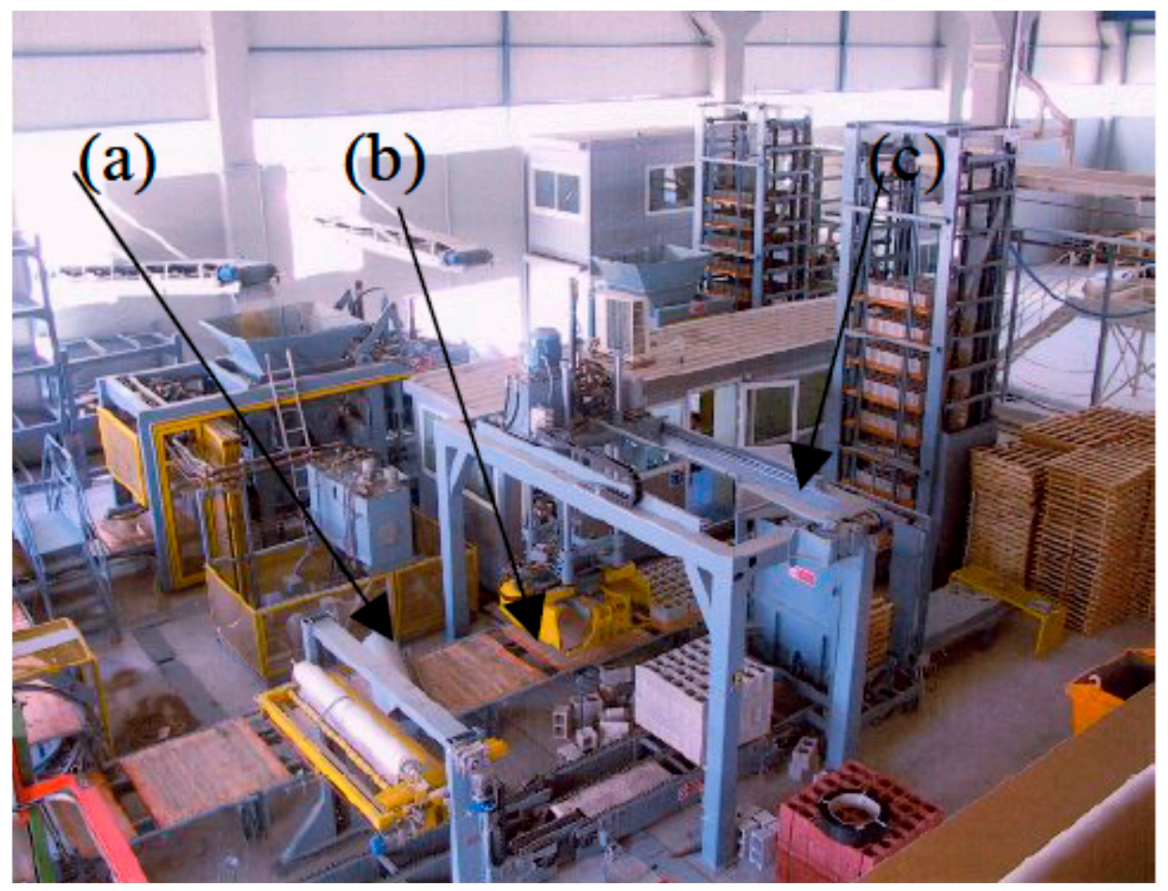

Figure 5. Example of production chain of blocks: (a) plate of fresh mix design; (b) vibro-compression mold box; (c) curing area.

The natural humidity of the components was monitored by electric sensors inside the hopper before adding water, furnishing values of natural humidity between $10 \%$ and $14 \%$. The curing phase was performed in a room with $20{ }^{\circ} \mathrm{C}$ and $50 \%$ humidity.

Some pilot trials, not reported in the present paper, have been firstly performed to evaluate the correct mix design for the production tests. The negative role of the cement mixed with cork granules was particularly evident. One week after the blocks' production, some preliminary tests were set up to verify the absence of penetration throughout a Vicat needle and a further imprint trial with a concentrated shear test on a sub-set of elements. One month after production, the mechanical tests were done. The average values of the apparent density were the following: $643 \mathrm{~kg} / \mathrm{m}^{3}$ (test A); $698 \mathrm{~kg} / \mathrm{m}^{3}$ (test B); $753 \mathrm{~kg} / \mathrm{m}^{3}$ (test C); $638 \mathrm{~kg} / \mathrm{m}^{3}$ (test D); $561 \mathrm{~kg} / \mathrm{m}^{3}$ (test E); the porosity after curing of the hemp blocks was between $12 \%$ and $16 \%$ while that of the cork was between $14 \%$ and $18 \%$. The porosity was measured by the difference of the weight between the dry state and the completely wet state.

\section{Mechanical Tests}

A series of flexural and compression collapse tests were performed in the laboratory 28 days after the blocks were manufactured. The tests were carried out on six-unit specimens $(250 \mathrm{~mm} \times 120 \mathrm{~mm}$ $\times 55 \mathrm{~mm}$ ) for each mix design type, as shown in Figure 6. We used a $250 \mathrm{KN}$ Galdabini machine (Galdabini, Varese, Italy) with a force tolerance of $\pm 5 \mathrm{~N}$ and a displacement tolerance of $\pm 0.001 \mathrm{~mm}$. The orientation of the tests was perpendicular to the direction of casting.

The flexural tests were performed by applying a concentrated transverse load in the middle of the unit, fixing a span of $200 \mathrm{~mm}$ with a transverse section of $55 \mathrm{~mm}$ (height) and $120 \mathrm{~mm}$ (thickness). The supports were implemented to avoid damages due to excessive local pressure. The loads were monotonically applied, by controlling the loading speed through the measures of the supports' relative displacement. The tests were made up to the complete failure of each specimen; the maximum load $P$ was detected through the internal dynamometer of the Galdabini machine and the corresponding vertical relative displacement $\mathrm{v}$ was measured. A picture of the flexural test and the main results are 
shown in Figure 7 and in Table 1, in terms of the average and standard deviation values of the collapse force and the corresponding displacement.
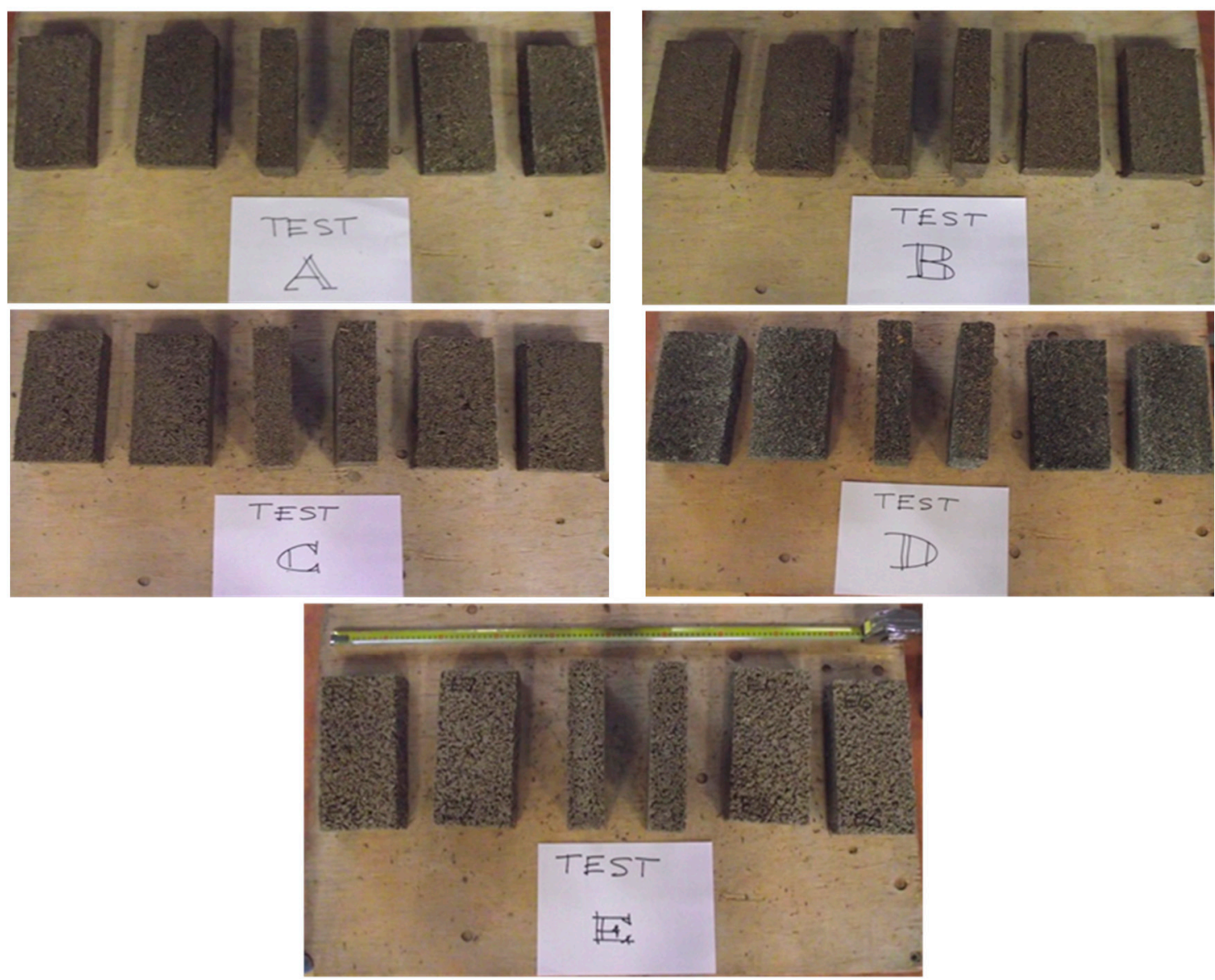

Figure 6. Specimens subjected to mechanical tests.

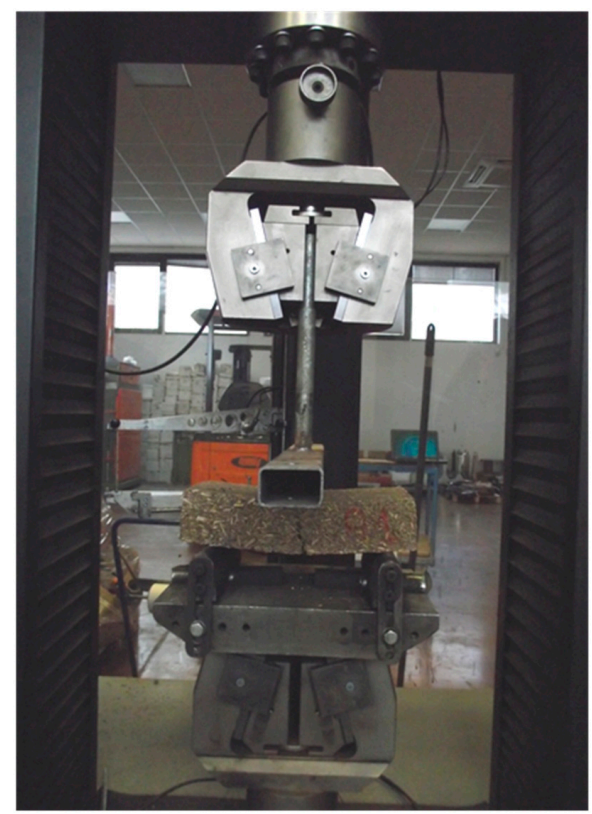

Figure 7. Setup of flexural tests. 
Table 1. Data from flexural tests.

\begin{tabular}{ccccc}
\hline & $\boldsymbol{P}$ & $\boldsymbol{\sigma}_{\boldsymbol{P}}$ & $\boldsymbol{v}$ & $\boldsymbol{\sigma}_{\boldsymbol{v}}$ \\
\hline Test A & 361 & 42 & 1.183 & 0.186 \\
Test B & 97 & 136 & 0.923 & 0.239 \\
Test C & 244 & 154 & 0.845 & 0.238 \\
Test D & 636 & 168 & 2.242 & 0.266 \\
Test E & 601 & 164 & 2.600 & 0.261 \\
\hline
\end{tabular}

$P$ : Transverse collapse force (average values) $-\mathrm{N}$; $v$ : limit displacement of $P$ (average values) $-\mathrm{mm} ; \sigma_{P}, \sigma_{v}$ standard deviation of $(P, v)$.

All the pieces, obtained from the bending failure of the specimens, have been used to perform compression tests up to collapse, through a steel squared base of $50 \mathrm{~mm}$ (Figure $8 \mathrm{a}, \mathrm{b}$ ).

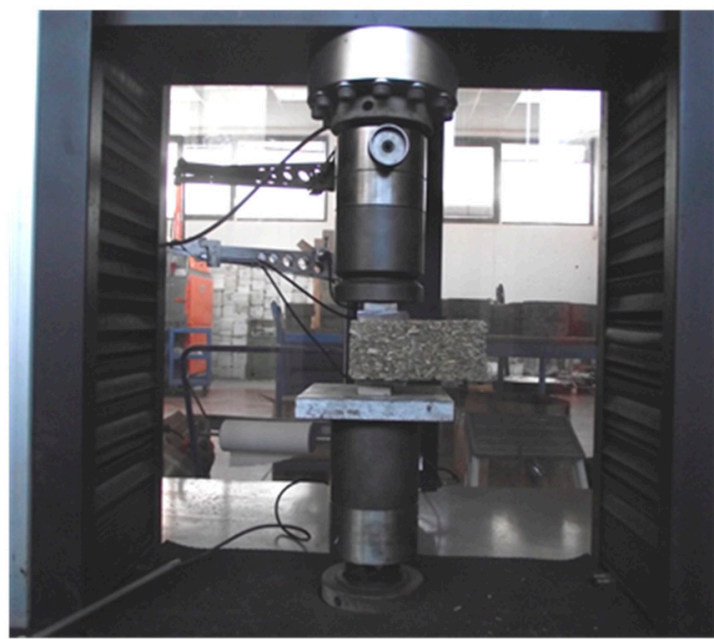

(a)

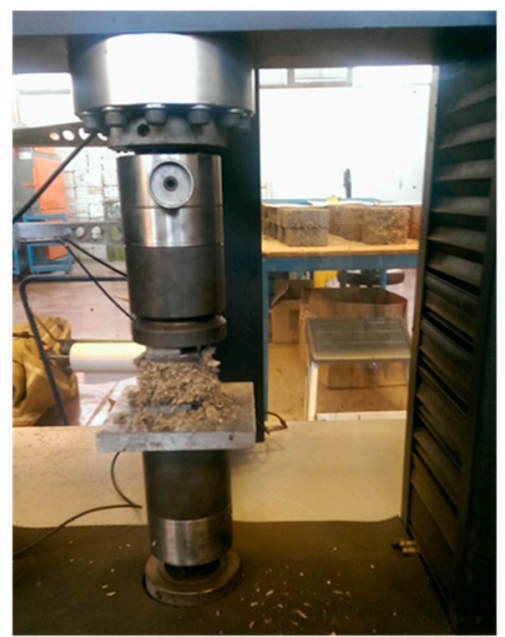

(b)

Figure 8. Setup of compression tests: (a) half specimen; (b) cubic specimen.

The specimen was applied on a free extremity, to minimize the containing effect due to the steel plate (Figure 8a). The results were compared with a subset of tests executed on a specimen with a cubic shape with a side of $50 \mathrm{~mm}$ (Figure 8b), verifying the correctness of the adopted set-up.

The summary of the results is reported in Table 2, in terms of the average and standard deviation values. The collapse force has been conventionally fixed, for type D (hemp and cement specimen), at $5.25 \%$ of strain and, for type E (cork specimen), at $7.00 \%$ of strain, due to the absence of explicit rupture. The typical surfaces of hemp and cork blocks are shown in Figure 9.

Table 2. Data from compression tests.

\begin{tabular}{ccccc}
\hline & $\boldsymbol{N}$ & $\boldsymbol{\sigma}_{\boldsymbol{N}}$ & $\boldsymbol{w}$ & $\boldsymbol{\sigma}_{\boldsymbol{w}}$ \\
\hline Test A & 1034 & 130 & 1.655 & 0.644 \\
Test B & 318 & 95 & 1.980 & 0.422 \\
Test C & 892 & 115 & 1.750 & 0.289 \\
Test D & 1556 & 232 & 2.625 & 0.250 \\
Test E & 1830 & 63 & 3.500 & 0.000 \\
\hline
\end{tabular}

$N$ : Axial collapse force (average values)—N; $w$ : limit displacement of $N$ (average values)— $\mathrm{mm} ; \sigma_{N}, \sigma_{w}$ standard deviation of $(N, w)$. 


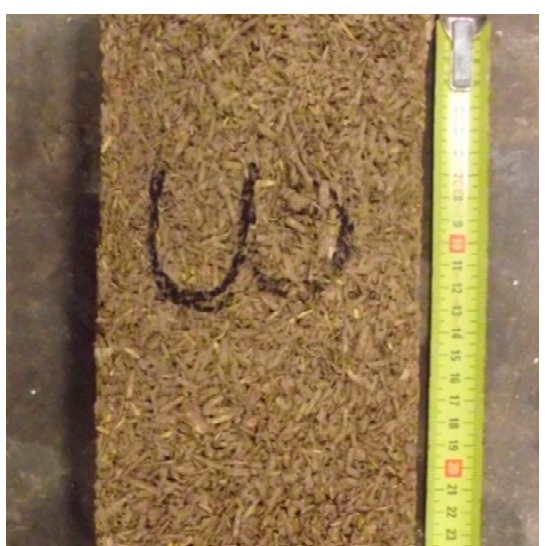

(a)

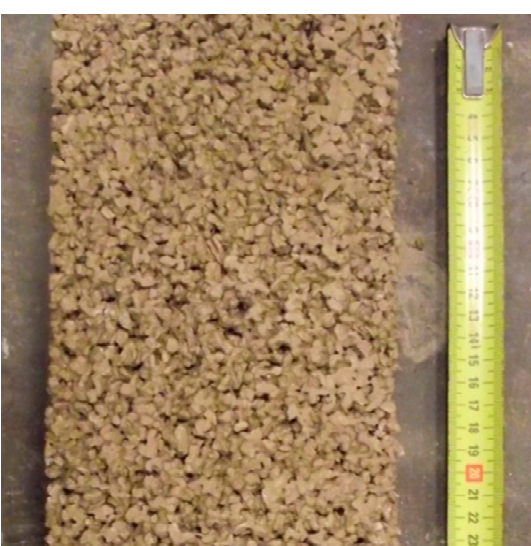

(b)

Figure 9. Specimen of hemp block-type A (a) and of cork block-type E (b).

The diagrams $\mathrm{N}-\mathrm{w}$ from compression tests of each production type are in the graphs of Figure 10.
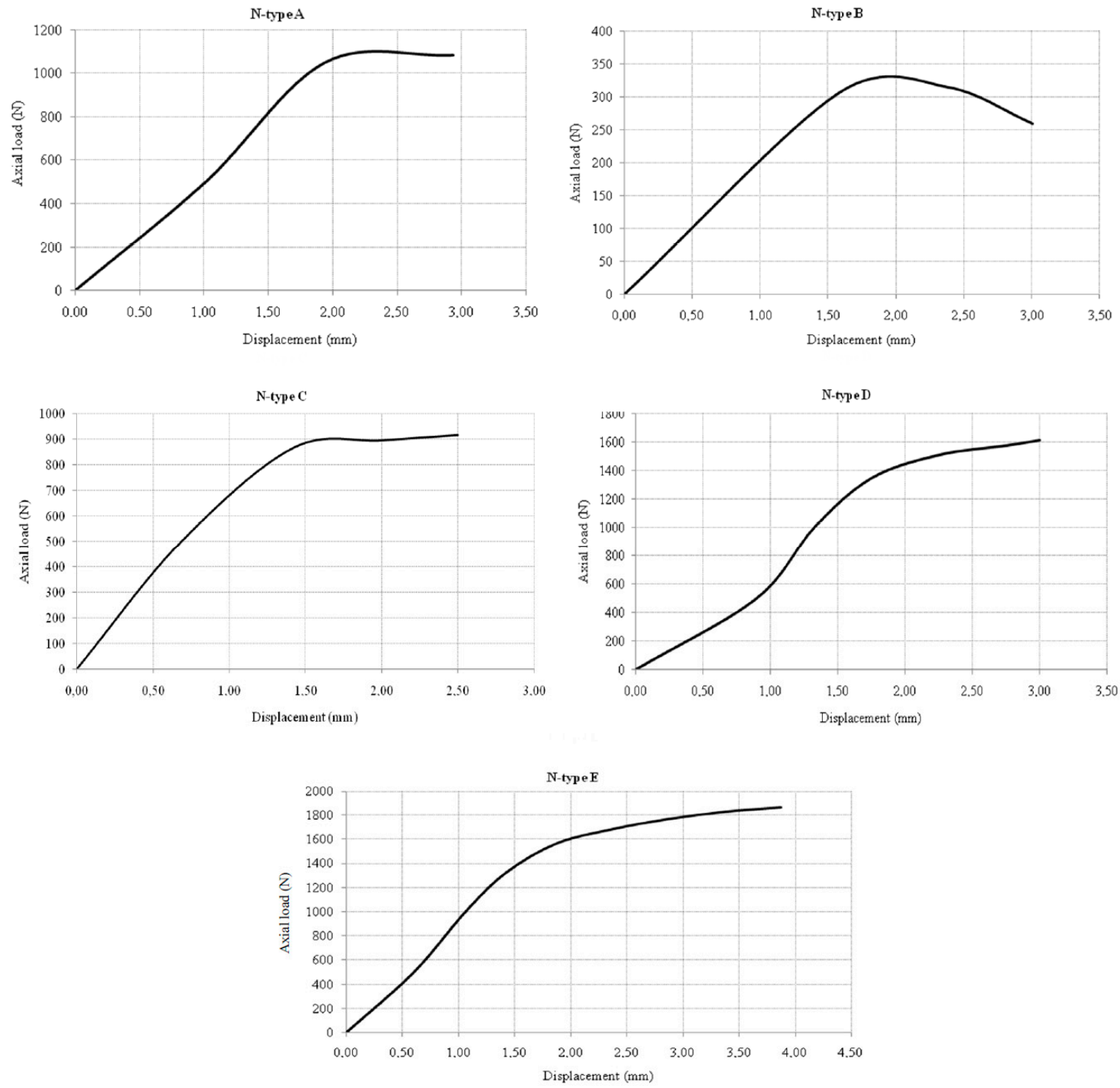

Figure 10. Axial load $\mathrm{N}(\mathrm{N})$ - vertical displacements $\mathrm{w}(\mathrm{mm})$ from the experimental tests. 


\section{Results}

The described mechanical tests provided conventional values of tension strength, compression strength and strain of collapse. The tension strength has been evaluated by the common Navier formula, deduced from ratio of the bending moment $\mathrm{M}=\mathrm{PL} / 4$ and resistance modulus $\mathrm{W}=\mathrm{bh}^{2} / 6$

$$
\sigma_{f}=1.5 \frac{P L}{b h^{2}}
$$

on a simply supported beam of $L=200 \mathrm{~mm} ; b=120 \mathrm{~mm} ; h=55 \mathrm{~mm}$. The compression strength has been referred to the steel plate area $A=2500 \mathrm{~mm}^{2}$, while the strain is measured on a length of $50 \mathrm{~mm}$. The mechanical results are reported in Table 3.

Table 3. Summary of the mechanical tests results.

\begin{tabular}{lccccc}
\hline & $\boldsymbol{m}$ & $\boldsymbol{\sigma}_{\boldsymbol{f}}$ & $\boldsymbol{\sigma}_{\boldsymbol{c}}$ & $\boldsymbol{\varepsilon}_{\boldsymbol{c} \boldsymbol{u}}$ & $\boldsymbol{E}_{\boldsymbol{c}}$ \\
\hline Test A & 643 & 0.299 & 0.414 & 0.0331 & 12,495 \\
Test B & 698 & 0.080 & 0.146 & 0.0431 & 3387 \\
Test C & 753 & 0.192 & 0.357 & 0.0350 & 12,190 \\
Test D & 638 & 0.4836 & 0.6222 & 0.0525 & 15,070 \\
Test E & 561 & 0.4502 & 0.7318 & 0.0700 & 18,570 \\
\hline
\end{tabular}

m: Apparent volumic mass $\left(\mathrm{kg} / \mathrm{m}^{3}\right) ; \sigma_{f}$ : flexural strength $(\mathrm{MPa}) ; \sigma_{c}$ : compression strength $(\mathrm{MPa}) ; \varepsilon_{c u}$ : limit compressive strain; $E_{c}$ : equivalent Young's modulus $(\mathrm{KPa})$.

\section{Discussion}

The mechanical test interpretation allowed us to make the following considerations addressed to an optimization of the proposed mix design types.

(a) The best mix design with hemp and NHL from a mechanical point of view is type A, where the percentage of NHL is lower with respect to type B, probably due to the excessive amount of NHL in comparison with the other components or the insufficient amount of water that did not permit a complete hydration process.

(b) The role of the cement in the mix design with hemp shives is not mechanically relevant with respect to the NHL: type C (with NHL and cement) has lower strength values, while the increment of strength due to the cement on type $\mathrm{D}$ is not significant.

(c) All the specimens show reduced strength values, a moderate difference between $\sigma_{f}$ and $\sigma_{c}$ and high collapse strain: it means that the elements are not effective for load-bearing use whether employed for non load-bearing purposes or combined with structural elements..

(d) All the specimens perform a ductile behavior due to the inelastic stress-strain law performed during the tests; joined with tension strength, they can be used in a composition with structural components (i.e., in the mix design of vibro-compressed concrete blocks) or for non-load-bearing applications on buildings (i.e., insulating panels, basement layers, separating walls).

(e) The cork specimens show the best mechanical performances for structural purposes, achieving the maximum strain and compression strength and the lightest weight from the set of the products considered, along with relatively high tension strength.

(f) Application on insulating panels, mainly for the cork composition, could be an interesting solution for masonry production in the field of bio-natural concrete elements.

(g) The difficulties of performing an equilibrated mix design in the presence of hemp fibers or shives should be taken into account to evaluate the percentage of water absorbed by the hemp by subtracting it from the curing reaction of the binder. The reduced compatibility of the hemp with cement should also be considered. 
(h) The production process and the mechanical tests show that the proposed mix design can be easily adopted in the vibro-compression unit procedure. Further investigations should be done to address the proposed mix designs to the described applications.

Acknowledgments: The present research is financed by the PRA 2016 program of the University of Pisa. Thanks to Arch. Riccardo Cecconi of the UNIBLOC Company and Antonio Tenore of Laboratorio Sigma for technical support.

Author Contributions: Mauro Sassu coordinated the activities. All the authors contributed in the same way to the research.

Conflicts of Interest: The authors declare no conflict of interest.

\section{References}

1. Andreini, M.; De Falco, A.; Giresini, L.; Sassu, M. Mechanical characterization of masonry walls with chaotic texture: Procedures and results of in-situ tests. Int. J. Archit. Herit. 2014, 8, 1-32. [CrossRef]

2. Andreini, M.; De Falco, A.; Giresini, L.; Sassu, M. Collapse of the historic city walls of Pistoia (Italy): Causes and possible interventions. Appl. Mech. Mater. 2013, 352, 1389-1392. [CrossRef]

3. Andreini, M.; De Falco, A.; Giresini, L.; Sassu, M. Structural damage in the cities of Reggiolo and Carpi after the earthquake on May 2012 in Emilia Romagna. Bull. Earthq. Eng. 2014, 12, 2445-2480. [CrossRef]

4. Sassu, M. The Reinforced Cut Wall (RCW): A Low-Cost Base Dissipator for Masonry Buildings. Earthq. Spectra 2006, 22, 533-554. [CrossRef]

5. De Falco, A.; Giresini, L.; Sassu, M. Temporary preventive seismic reinforcements on historic churches: Numerical modeling of San Frediano in Pisa. Appl. Mech. Mater. 2013, 352, 1393-1396. [CrossRef]

6. Sassu, M. Biaxiality effect on the energy dissipated by elastoplastic base-isolators. J. Eng. Mech. 2003, 129, 607-612. [CrossRef]

7. De Bruijn, P. Material properties and full-scale rain exposure of lime-hemp concrete walls. Acta Univ. Agric. Suec. 2012, 68, 1652-6880.

8. Elfordy, S.; Lucas, F.; Tancret, F.; Scudeller, Y.; Goudet, L. Mechanical and thermal properties of lime and hemp concrete ("hempcrete") manufactured by a projection process. Constr. Build. Mater. 2008, 22, 2116-2123. [CrossRef]

9. Diquélou, Y.; Gourlay, E.; Arnaud, L.; Kurek, B. Influence of binder characteristics on the setting and hardening of hemp lightweight concrete. Constr. Build. Mater. 2016, 112, 1506-1517. [CrossRef]

10. Arnaud, L.; Gourlay, E. Experimental study of parameters influencing mechanical properties of hemp concretes. Constr. Build. Mater. 2012, 28, 50-56. [CrossRef]

11. Gil, L. New Cork-Based Materials and Applications. Materials 2015, 8, 625-637. [CrossRef]

12. Lu, N.; Korman, T. Engineering Sustainable Construction Material: Hemp-Fiber-Reinforced Composite with Re-cycled High-Density Polyethylene Matrix. J. Archit. Eng. 2013, 19, 204-208. [CrossRef]

13. Eires, R.; Nunes, J.P.; Fanguiero, R.; Jalali, S.; Camoes, A. New eco-friendly hybrid composite materials for civil construction. In Proceedings of the 12th European Conference on Composite Materials, Biarriz, France, 29 August-1 September 2006.

14. Bütschi, P.Y.; Deschenaux, C.; Miao, B.; Srivastava, N.K. Caractérisation d'une maçonnerie composée d'éléments en aggloméré de chanvre. Rev. Can. Génie Civ. 2004, 31, 526-529. (In French) [CrossRef]

15. Woolley, T. Natural Building: A Guide to Materials and Techniques; The Crowood Press Ltd.: Marlborough, UK, 2006.

16. Lawrence, M.; Fodde, E.; Paine, K.; Walker, P. Hygrothermal performance of an experimental hemp-lime building. Key Eng. Mater. 2012, 517, 413-421. [CrossRef]

17. Martins, C.; Dias, A.M.P.G.; Costa, R.; Santos, P. Environmentally friendly high performance timber-concrete panel. Constr. Build. Mater. 2016, 102, 1060-1069. [CrossRef]

18. Silva Pereira, C.; Soares, G.A.M.; Oliveira, A.C.; Rosa, M.E.; Pereira, H.; Moreno, N.; San Romao, M.V. Effect of fungal colonization on mechanical performance of cork. Int. Biodeterior. Biodegrad. 2006, 57, 244-250. [CrossRef]

19. Pervais, M. Carbon storage potential in natural fiber composites. Resour. Conserv. Recycl. 2003, 39, 325-340. [CrossRef] 
20. Giresini, L.; Fragiacomo, M.; Lourenço, P.B. Comparison between rocking analysis and kinematic analysis for the dynamic out-of-plane behavior of masonry walls. Earthq. Eng. Struct. Dyn. 2015, 44, 2359-2376. [CrossRef]

21. Giresini, L.; Fragiacomo, M.; Sassu, M. Rocking analysis of masonry walls interacting with roofs. Eng. Struct. 2015, 116, 107-120. [CrossRef]

22. Giresini, L. Energy-based method for identifying vulnerable macro-elements in historic masonry churches. Bull. Earthq. Eng. 2015, 44, 2359-2376. [CrossRef]

23. Giresini, L.; Sassu, M. Horizontally restrained rocking blocks: Evaluation of the role of boundary conditions with static and dynamic approaches. Bull. Earthq. Eng. 2016. [CrossRef]

(C) 2016 by the authors; licensee MDPI, Basel, Switzerland. This article is an open access article distributed under the terms and conditions of the Creative Commons Attribution (CC-BY) license (http://creativecommons.org/licenses/by/4.0/). 